Article

\title{
Advanced Manufacturing in Civil Engineering
}

\author{
Ana S. Guimarães ${ }^{1}$, João M. P. Q. Delgado ${ }^{1, *(1)}$ and Sandra S. Lucas ${ }^{2}$ (i) \\ 1 Institute of R\&D in Structures and Construction (CONSTRUCT-LFC), Department of Civil Engineering, \\ Faculty of Engineering, University of Porto, 4200-465 Porto, Portugal; anasofia@fe.up.pt \\ 2 Unit of Structural Design, Department of the Built Environment, Eindhoven University of Technology, \\ P.O. Box 513, 5600 MB Eindhoven, The Netherlands; s.s.d.o.lucas@tue.nl \\ * Correspondence: jdelgado@fe.up.pt; Tel.: +351-225081404
}

Citation: Guimarães, A.S.; Delgado, J.M.P.Q.; Lucas, S.S. Advanced

Manufacturing in Civil Engineering. Energies 2021, 14, 4474. https:// doi.org/10.3390/en14154474

Received: 16 June 2021

Accepted: 22 July 2021

Published: 24 July 2021

Publisher's Note: MDPI stays neutral with regard to jurisdictional claims in published maps and institutional affiliations.

Copyright: (c) 2021 by the authors. Licensee MDPI, Basel, Switzerland. This article is an open access article distributed under the terms and conditions of the Creative Commons Attribution (CC BY) license (https:// creativecommons.org/licenses/by/ $4.0 /)$.

\begin{abstract}
The main goal of this work is the analysis of potential energy and green benefits of 3D printing on building construction. Current literature reports a considerable number of benefits for 3D printing, namely, reduction of material use, lower operational costs and time-saving. The authors also mention design freedom, higher efficiency, productivity and quality. This work presents the latest developments in 3D printing in civil engineering, namely, a review of the last 3D printing projects and the limitations of construction 3D printing with a focus on large-scale applications, technology costs, mix development and optimisation and thermal behaviour.
\end{abstract}

Keywords: 3D printing; additive manufacturing; building automation; civil engineering

\section{Introduction}

In recent years, building procedures have been essentially based on manual labour, which is one of the reasons why construction activity is considered low-tech with low levels of innovation. The activity needs to be more viable and become more positive in attaining the technological level as other industrial activities. In recent years, digital technologies, including Building Information Modelling (BIM) and Virtual Reality (VR) have started to be implemented on a large scale. Additive Manufacturing (AM) combined with 3D printing is an obvious step for large-scale production in civil engineering.

Joining industry 4.0 has become inevitable for the construction sector, and this goal has defined the most recent developments in the field. The 3D printing (3DP) of concrete is slowly gaining momentum, and it is now possible to print an entire building with this technique $[1,2]$.

The European Commission reported that buildings are the single largest energy consumer in Europe and are a major contributor to non-renewable resources depletion. With the intensification in consumer's requirements, concerns with climate change and the increasing need for rapid urbanisation, it is important to establish more efficient construction methods able to overcome the lack of interoperability and productivity currently present in the construction sector. Buildings consume over $40 \%$ of annual global energy-as embodied and operating energy-which contributes to approximately $40 \%$ of global carbon emissions [3].

Warszawski and Navon [4] showed other issues that should also be considered in the construction industry, such as low work efficiency and a high accident rate, insufficiently skilled workforce and difficulty in applying quality control at the construction site.

Construction 3D printing, when associated with traditional approaches, not only revealed important economic, environmental and construction rewards, such as a reduction in building time and waste, mass customisation and complex architectural forms, but also demonstrates an auspicious trend towards Digital Transformation in industry because of the possible association of 3D printing with building information modelling and artificial intelligence $(\mathrm{AI})$. 
In the last 10 years, the interest in 3D printing construction research has increased significantly. In this work, a systematic and extensive literature review was performed in order to analyse the application of 3D printing technology on building construction (civil engineering), namely, its association with BIM and additive manufacturing. An important tool in the success of 3D printing in building construction is the BIM method in order to avoid errors and conflicts at the design stage. BIM is an important source of geometric information for automated, commercially existing, large-scale, 3D-printing machines in order to scheduling and assembly the sequence information as well as to maintain safety and productivity $[4,5]$. The development of additive manufacturing processes is always reliant on the level of technological progress and its commercial relevance [6,7]. It is well-known that additive manufacturing (AM) depends on technological progress and commercial relevance. It should be noted that AM represents, in a digital form, all the complete processes of building construction, which includes material science and engineering (areas of civil engineering knowledge).

The main benefits of additive manufacturing with $3 \mathrm{D}$ printing to the construction industry are $[7,8]$ :

- Shorter building time: the construction time of a structural wall could be reduced by $35 \%$ using 3D printing when compared to masonry construction [9];

- Mass customisation and the potential for $\mathrm{CO}_{2}$ footprint reduction [10];

- Minimising material use: the 3D-printing process allows for greater accuracy of the amount of material the object requires, which contributes to a waste reduction;

- Generation of complex shape design at controlled costs: it is possible to develop new structures that are difficult to produce using current construction methods;

- Reduction of arduous human labour: the labour-intensive requirements for traditional construction can be reduced with a 3D printing process;

- The creativity of architects and designers is increased;

- The thermal and acoustic properties of the buildings are optimised automatically [11].

The Web of Science and Scopus databases were reviewed until mid-2021 for Englishlanguage papers, without any other restrictions. The literature analysis showed that studies of $3 \mathrm{D}$ printing technology in civil engineering or construction technology were fewer than in other engineering areas. A total number of approximately 120 publications of papers in journals and conference proceedings were found. Only approximately 20 publications contain the words "3D printing" and "BIM" in topics associated with building construction, and approximately 70 publications contain the words "3D printing" and "Additive Manufacturing" for the same topic. These values are insufficient compared to research in other industries, and the number of studies on 3D printing applications should increase in the construction industry. Moreover, if the origin of the publications is examined, about $50 \%$ of the total publications are coming from the USA and UK, more precisely, from the Massachusetts Institute of Technology (MIT), Loughborough University and the University of Southern California.

\section{3D Printing in Civil Engineering}

The construction industry took a long time to perceive the enormous potential of $3 \mathrm{D}$ printing. One possible explanation is the fact that, initially, the first $3 \mathrm{D}$ printers were only able to print small-scale objects and were very limited in number and availability. However, more recently, several construction companies and universities started investing and developing new ways of incorporating $3 \mathrm{D}$ printing technology to provide innovative construction methods [12]. The considerable progress in this research area should be noted to have been conducted by four research teams: the University of Southern California in conjunction with the Contour Crafting team, the Loughborough University with Hyundai Engineering and Construction team, the heSam University with XTreeE team and the Eindhoven University of Technology.

In building construction, in general, several additive manufacturing techniques can be used, as binder jetting, material jetting, extrusion of material, direct energy deposition, 
powder bed fusion, material deposition method, sheet lamination and vat polymerisation. However, in civil and architectural engineering, the need to print large-scale objects means that the material deposition method (MDM) and binder jetting are the most-used additive manufacturing techniques.

\subsection{Binder Jetting}

This is one of the most-used 3D printing processes for Additive Manufacturing, where objects are created by depositing a binder on a bed of sand that will agglomerate (powder bed) at locations provided by the CAD model. This is a repetitive process of depositing thin layers of binder until the whole 3D object is complete [13]. At the end of the process, the non-agglomerated sand is removed with the help of a vacuum cleaner, and the sand removed is recycled and deployed for another printing task [14].

The layer thickness is determined by the binder penetration, so due to a minimal distance between layers, this methodology results in a good surface finish [15].

\section{D-Shape}

The D-shape is a method of digital construction developed by Enrico Dini [16], which uses a binder jetting 3D printer and layers of powder and adhesive rather than the cementlike paste. This technology uses selectively hardened powder deposition by locally applying a binder material. Sand layers are laid to the desired thickness and then compressed. Wolfs [17] showed that this technique could print up to $6 \times 6 \times 6 \mathrm{~m}$ from architectural structures. However, as described by Lim et al. [18], this technique presents a disadvantage: the sand has to be scattered and compressed for each layer. At the end of the element construction, the excess sand is removed.

\subsection{Material Deposition Method (MDM)}

The material deposition method is another 3D-printing process that uses a CAD model to lay material successively. The material deposition method could be divided in:

- Material extrusion: in this method, a layer of mortar or clay, with enough stiffness to support the following upper layers, is deposited and hardened [19];

- 3D-printed formworks filled with mortar or concrete. This technology is based on a triple wall of 3D-printed materials, i.e., two-polymer foam (polyurethane)-printed walls are used to enclose the third wall made of concrete.

The main 3D-printing techniques that use the MDM method for the fabrication process are contour crafting, concrete printing, stick dispenser, digital construction platform, flowbased fabrication, mini-builders and mesh-mould [20].

\subsubsection{Contour Crafting}

Contour Crafting (CC) is defined as a layer-by-layer construction technology controlled by a computer (CAD model), mainly for small structures, designed and developed at the University of Southern California. This pioneering technique of printing [21] with ceramic and cementitious materials is easy to use, delivers rapid production, substantial cost savings and waste reduction and served as the basis for the development of other technologies. The technology has a construction rate of $3 \mathrm{~min} / \mathrm{m}^{2}$ to elevate the walls; it can build a house of $200 \mathrm{~m}^{2}$ in just $20 \mathrm{~h}$, with a workforce of only four people.

This manufacturing method combines two processes: the extrusion process to create object surfaces and the filling process to build, in layers, the object core [22]. This hybrid method presents enormous economic potential, and it was designed to provide superior safety (a significant reduction of workplace injuries), an environmental impact reduction (energy savings and on-site waste disposal) and a better quality of life [22]. As described by Lim et al. [18], this 3D printing technique presents several disadvantages as the excessive number of steps to build layers up to $20 \mathrm{~mm}$ high, the mould is not discarded and becomes a part of the wall, etc. 


\subsubsection{Concrete Printing}

Concrete printing $(\mathrm{CP})$ is another 3D-printing technology developed by Loughborough University that involves the extrusion of cement mortar in a layer-by-layer process.

As contour crafting technology, concrete printing is a construction process based on cement mortar extrusion; however, a lower deposition resolution allows greater control of internal and external geometries [18].

As empathised by Yossef and Chen [23], the advantages presented by the contour crafting technique stimulated Loughborough researchers to develop a concrete printing machine, with a frame of $5.4 \mathrm{~m} \times 4.4 \mathrm{~m} \times 5.4 \mathrm{~m}$ (height) and a beam-moving print head with a $9 \mathrm{~mm}$ nozzle to provide the extrusion material. The experimental program, conducted by Le et al. [24] to find out the best mix design for high-performance concrete, showed that a fibre-reinforced composition with superplasticisers and retardant for increase workability and strength could be a solution to maintain the hardened properties (100 MPa compressive strength and $10 \mathrm{MPa}$ flexural strength at 28 days), workability and extrusion requirements.

In summary, the three main 3D-printing methods (contour crafting, concrete printing and D-shape) have served as a reference for the emergence of new technologies and recent experiences in building printing. These methods, as opposed to the traditional building construction method, present a considerable waste reduction. All three technologies, since they are based on additive manufacturing and designed for concrete printing, have many similarities in terms of the printing process; however, each technology has distinct characteristics. CC is designed to be a crane mounted device for in situ applications; concrete printing was initially developed for off-site applications but, thanks to better control of the fresh material, has now moved to on-site printing [25]. D-Shape remains a manufacturing process for off-site fabrication [8]. For Alwi et al. [7], the extrusion printing process offers several advantages over the other methods; namely, the largest part of the drawing becomes independent of the material to be extruded. This allows a degree of flexibility, so some design decisions can be postponed or decoupled from each other. In a dust deposition system such as D-Shape, the exact characteristics of the media should be known early in the design process as its confinement and delivery become an integral part of the mechanical design of the printer. On the other hand, for an extrusion-based machine, if better material is developed within the printer's life, a change in the print head and media supply, while maintaining intact mechanical structure, is necessary. Another difference between these technologies is the solutions developed to create the wall openings. As CC produces largely compressed vertical elements, the doors or windows openings require a lintel to prevent cantilever problems. The D-Shape and concrete printing methods need additional support for protruding or freeform structures. D-shape is a process based on dust deposition, so it uses the material not consolidated for support [18].

The print resolution (in terms of layer thickness) ranges from 4 to $6 \mathrm{~mm}$ in concrete printing and D-Shape technologies to approximately 13 millimetres in CC. Concrete printing achieves higher speeds compared with CC and D-Shape. CC needs lower speeds to ensure proper bonding between layers and D-Shape, due to the complexity of the process and the need to remove excess powder, although faster than CC cannot achieve the speed of concrete printing. For concrete printing, speed is only limited by the bond strength between layers and the geometry of the object [26].

\section{Results and Discussion}

Over the last decade, several 3D printing projects have been completed worldwide. The most relevant projects, completed and undergoing, are described in Table 1. The examples below are good evidence that 3D printing, once considered a niche technology, is gaining increasing relevance in the construction sector. 
Table 1. Examples of civil engineering constructions using 3D printing.

\section{D Printing Construction}

Project Milestone

The Netherlands (2020)

China

(2020)

Quarantine Wards

DFAB House

Switzerland (2019)

(2020)

El Salvador (2018)

\section{Description}

Status

Project Milestone is a business home project based on 3D concrete printing

that started in 2018. The buildings will all be used, they will meet all

contemporary and common requirements, and they will be acquired and let

out by a realty company. The five houses will be located in the Meerhoven district of Eindhoven.

A Chinese company, Winsun Building Technique Co. Ltd., donated

15 wards made using their 3D printing technology to a hospital in the

province of Hubei. These $10 \mathrm{~m}^{2}$ wards were prepared with a mix of

Army Barracks

USA

(2018) industrial recycled waste and cement and can withstand strong winds and earthquakes. According to the company, the wards can be produced in just $2 \mathrm{~h}$ [27].

DFAB House is a 3D project of an inhabited house developed by ETH

Zurich and industrial partners and constructed in 2019. This house, $200 \mathrm{~m}^{2}$, was constructed with the help of robots and 3D printers in order to test, under real-life conditions, new construction and energy technologies to archive more efficient and sustainable 3D printing houses.

ICON, a construction company in Austin, Texas, in collaboration with New Story, a non-profit housing organisation, appeared with a 3D printer that can construct move-in-ready houses for just 4000 USD. The printer, named "Vulcan", can print a $60 \mathrm{~m}^{2}$, single-story cement home in $24 \mathrm{~h}$. The printer was transported to Latin America to build a 3D-printed community in El Salvador [28,29] in 2018 and, more recently, another community in Mexico as part of a commitment to fight global homelessness.

A group of US army researchers 3D printed a $47 \mathrm{~m}^{2}$ concrete barrack in just $40 \mathrm{~h}$. Their main goal is to build stronger and durable barracks faster than traditional methods. The possibility of building on-site allows for faster

$$
\text { construction in remote areas [30]. }
$$

Completed

Completed

This 3D-printed, low-cost house, $12 \mathrm{~m}^{2}$, was constructed with raw soil and natural waste from the rice production chain, i.e., natural materials from the surroundings. The main goal associated with this project, which applies Crane WASP technology, was to construct low-cost houses with natural materials and without necessities of heating or air-conditioning systems.
Completed
Italy
$(2018)$ 
Table 1. Cont.

3D Printing Construction

The BOD

Denmark (2018)

Country (Year)

\section{Description}

This first European 3D-printed house, with $50 \mathrm{~m}^{2}$, was constructed in

Denmark with the participation of Danish-Government-funded project "3D

Construction Printing". This house, entitled "The BOD" (Building on

Demand), was designed by 3D Prinhuset, and the only straight elements

observed in this house are the doors and the windows. One important

feature of this 3D-printing construction was the building foundations,

which were partially 3D printed in order to avoid the problems associated with the traditional building techniques, i.e., a building construction without straight elements.

An automated robotic system, named "BatiPrint3D", was used to print an entire house in just a few days. The house is currently occupied by a French

family. The project was led by the University of Nantes and included a

France

consortium of scientists, manufacturers and public stakeholders. The aim is to make 3D printing feasible for affordable housing.

The pedestrian footbridge, with a length of $12 \mathrm{~m}$ and $1.75 \mathrm{~m}$ in width, was 3D-printed with micro-reinforced concrete material. The project was

Pedestrian bridge

Spain (2017)

列 order to eliminate material waste, the authors used an innovative parametric design technique.

Another example is the world's first printed, reinforced concrete bridge,

which was installed in the small village of Gemert, Netherlands. The bridge, $8 \mathrm{~m}$ long and $3.5 \mathrm{~m}$ in width was printed and tested (application of 5-tonne load with no failure) at the Eindhoven University of Technology (TU/e). An important detail is that the researchers were able to build this reinforced concrete bridge by developing a method to run a stainless steel wire along the nozzle of the printer to make sure that steel reinforcements existed between every layer of concrete printed, thus providing extra reinforcement to the system. This method could hopefully start more research and development on 3D-printed reinforced concrete, which is what all

constructions companies will be searching for in any investment in such technology [31].
3D-Printed Concrete Bridge

The Netherlands (2017)

Completed

Completed

Completed 
Table 1. Cont.

3D Printing Construction

R\&Drone Laboratory

(2017)
Country (Year)

\section{Description}

Status

The R\&Drone Laboratory was built in 2017. CyBe was in charge as a

subcontractor for the engineering and construction of the 3D printing operations in the building. They used a mobile printer that was transported

to Dubai, and the elements were printed on-site. During printing,

Completed

temperatures reached 40 degrees Celsius, making the mortar's final setting reached in just $5 \mathrm{~min}$ [32].

United Arab Emirates National Innovation committee was constructed an

office building with 3D printers called "Office of the Future". The

3D-printed office is a fully functional building featuring electricity, water and telecommunications and air-conditioning systems [33]. The WinSun Global Company, from China, was the contractor on this project. Winsun developed a mix design composed of a cement to fine aggregate ratio equal to 0.78 , a sand to fine aggregate ratio equal to 0.50 and a water/cement ratio of 0.49 . The proposed combination ratio produces a concrete mix that has compressive strength up to $55 \mathrm{~N} / \mathrm{mm}^{2}$, which is more than the minimum requirement of $17 \mathrm{~N} / \mathrm{mm}^{2}$ according to construction codes. The 3D-printed office was produced in China, and after the parts had been printed, it was assembled on site. The total duration of project was several weeks; it was reduced construction (labour) costs by about $50-80 \%$ and the reduction in construction waste by $30-60 \%$ [31]. This office building of $240 \mathrm{~m}^{2}$ was built in 17 days, using reinforced concrete, fibre-reinforced plastic and glass fibre-reinforced gypsum with a total cost of 140,000 USD.

The Apis Cor House, a 3D-printed home, was built in Moscow, in just $24 \mathrm{~h}$, by the American company Apis Cor and the Russian company PIK Group. The main outcomes of this house, $38 \mathrm{~m}^{2}$, were the low cost (10,000 USD), the construction time $(24 \mathrm{~h})$ and the fact that the house was built entirely on-site using only a mobile 3D printer. All the foundations and walls were printed with a concrete mixture, and only the windows and doors were added after
Completed

Completed

$$
\text { construction finished [7]. }
$$

Apis Cor House

Russia (2016) 
Table 1. Cont.

\section{D Printing Construction}

Villa

6-storey apartment building

China (2016)

USA (2016)

\section{Description}

Status

Villa, $400 \mathrm{~m}^{2}$, was built/printed on-site in only 45 days by the Chinese

company HuaShang Tengda. The Chinese company described this

construction as extremely durable due to the fact that the walls are made

with 20 tonnes of C30-grade concrete and measuring $250 \mathrm{~mm}$ thickness, and

resistant, as the seismic tests showed that this $3 \mathrm{D}$ printing villa should be

capable of resisting a level-eight earthquake on the Richter scale.

Another Chinese company WinSun, using a 3D printer $6.1 \mathrm{~m}$ in height,

$40.2 \mathrm{~m}$ in length and $10.1 \mathrm{~m}$ in width, has 3D-printed a six-storey apartment

building [34]. WinSun indicated that the apartment walls and other

structural components were fabricated off-site and assembled on-site.

Additionally, the company informed that the apartments were constructed

with a patented and undisclosed mixture concrete formula that comprises

the use of recycled construction material (i.e., fibreglass, special bonding

medium and concrete). This mixture was described as flexible, self-sustaining and resistant to earthquakes.

As described by Eddie [35], the world's first 3D-printed hotel villa was constructed, in 2015, in Philippines. It was described as the first commercia

building, $10.5 \mathrm{~m}$ by $12.5 \mathrm{~m}$ and a high of $3 \mathrm{~m}$. This building with 2

bedrooms, an addition to the Lewis Grand Hotel, was 3D-printed in

approximately $100 \mathrm{~h}$. Eddie [35] showed that the 3D-printed hotel villa

Completed
Completed
Completed 


\section{Advantages of 3D Printing in Building Construction}

\subsection{Waste Reduction and Use of Alternative Binders}

Although in the early days of 3D printing of concrete, the mixes had a high cement content, around $40-50 \%$, as the technology evolved, mixes became lower in cement, which was replaced by other alternative binders [36-41]. Fly ash and slag are now used as a cement replacement or activated in 3D-printed geopolymers [42-44]. Ting et al. [45] tried to replace sand with recycled glass in 3D printing, and although the results were not as good as the sand-cement mix, the results show a promising trajectory to use recycled aggregates in 3DP mixes.

Companies such as Winsun and CyBe are developing new solutions to increase the use of recycled materials, such as calcined clay and fly ash, creating optimised concrete. These innovations do not only help the environment by reducing the use of mass-manufactured materials but can help developing nations where the material's cost is very high. Literature shows that a gradual application of 3D printing has a big overall impact on large scale production, with a noticeable reduction in cement/water ratio usage, which means less cement is needed, which in turn can reduce energy usage for cement manufacturers [46].

\subsection{Impact on Human Labour}

Buildings are becoming more complex and construction sites less safe for construction workers; worldwide, the rate of accidents in the sector is one of the highest, which, combined with shortages of skilled labour, make the industry one of the least efficient. Automation, by cutting the dependency on human labour, reduces the number of accidents, injuries and illnesses. Naturally, a new set of skills is required to work with 3D printing, and the construction sector will have to adapt by providing training to workers and hiring new staff. A transition that follows what already happened in other industries will bring the construction industry to a higher technological level.

\subsection{Costs and Speed}

Automation in building construction can significantly reduce the overall expenditures of construction projects. It is possible to reduce the material costs by over $50 \%$, and the prefabrication of concrete structures such as walls, roof systems and floor panels can have a considerable overall cost reduction because of the potential to reduce the weight by $54 \%$ through the material volume reduction [10].

The technology of 3D printers also saves time by providing continuous printing that can only be stopped when desired. Structures that would typically take months to construct can be built within days of the project initiation date. Another added value of the 3DP technology that contributes to improved sustainability and reduced costs is the absence of formwork [47]. Formwork, in traditional construction, accounts for $28-50 \%$ of the total cost of a concrete structure.

Weller et al. [48] analysed several principles relevant to manufacturers based on economic models and concluded that additive manufacturing offers more flexibility, highly customised products with no cost penalties and with rapid manufacturing, resulting in lower prices for the consumers.

\subsection{Design Complexity}

3DP allows for high design freedom, only limited by computational capabilities, opening a whole new range of possibilities for architects and engineers to create custom-made buildings. Some complex shapes have been achieved in the past with conventional formwork; however, additive manufacturing provides more freedom without increasing costs. With 3DP, the environmental impact of a structure does not increase with its complexity, as it happens with conventional structures [49]. 


\section{Limitations of Construction 3D Printing}

\subsection{Large-Scale Applications}

The application of 3DP at a large scale, though workable, still poses some challenges. The debate on how to ensure a constant supply of raw material is still ongoing. Most projects use conventional batching, but the possibility of micro-batching or mixing at the nozzle are also being explored.

The shape of the extrusion nozzle is usually rectangular or circular, and it is already known that its shape and size can influence the printing speed, the way each printed layer is deposited and the effect when printing changes direction [46].

When the scale of the element increases and the printing time is extended, there is an increase in temperature caused by heating in the pump and friction in the pump and hose. The impact of temperature in the pumpability, extrudability and early setting of the material is still not completely understood, but the effect is visible in the changes observed in the material. Bigger elements also have a higher risk of collapsing under self-weight deformation, and so far, the only option is to limit the height of the printed object [50].

Scaling up the printing process means increasing printing speed and the size of the object, which can cause poor layer adhesion because longer printing paths can make the cycle too long. This can be controlled by changing the geometry of the printed object and the process parameters [46].

\subsection{Technology Costs}

There is still not enough research to predict what will be the costs for the technology once it is fully implemented; however, it is acceptable to assume that 3DP will contribute to minimising the overall cost of a project. Formwork contributes to approximately $40 \%$ of the total expenditure, so its absence can reduce the overall budget and also have a positive impact on reducing $\mathrm{CO}_{2}$ emissions. The same applies to the reduction of waste and raw materials, a consequence of the efficiency of the process. As with any new technology, during the early implementation stage, the cost can be higher because the technology is not yet fully optimised. Among the implementation costs, one possible obstacle to large-scale applications can be the lack of labour resources-the technology is new and it will take time to have a good number of specialists and technical staff trained in 3DP. The transportation and placement costs also need to be factored in - these come with an environmental impact too, and though prices for equipment will tend to decrease, the cost for the equipment and maintenance are still high.

\subsection{Mix Development and Optimisation}

Mix development and optimisation are still achieved by trial and error until a suitable mix with adequate pumpability, extrudability and buildability is achieved. The mixes contain a high volume of fine particles — besides cement and sand — and can contain silica fume, fly ash and limestone filler. One of the major issues is the high cement content, which can go up to $50 \%$ in some cases, which significantly increases the carbon footprint of 3DP [51-53].

The development of more sustainable alternatives became, therefore, a priority. In geopolymers, cement has been replaced by alternative binders (slag and fly ash) that are activated using an alkaline solution; however, there is a limited worldwide supply of both, and this will not be a viable alternative to replace cement in construction, not even if 3DP remains a niche market.

There is also a lack of understanding of how these mixes behave in the fresh state, particularly during the first $90 \mathrm{~min}$, and conventional tests are not enough to control the fresh behaviour adequately. A way to overcome this is to use several methods to establish a reliable comparison and obtain sufficient data for modelling and predicting the material's performance. 


\subsection{Thermal Behaviour}

For the state of the art, the construction industry was put into perspective evaluating the benefits and challenges of additive manufacturing of large-scale components, the 3D printing processes commonly applied in the construction industry, materials development and experimental applications, showing that thermal studies are scarcely found or done.

Among thermal innovations in the sector of building construction, Yoon [54] investigated the use of shape memory polymer (SMP) as an activator of shading devices to be implemented to adaptive building façades. To testify the 3D-printing feasibility of different kinetic SMP cell types and to examine their shape-changing behaviours by heat, an FFF 3D printer named "Cubicon Single Plus" was used to fabricate SMP components.

Another study by Sarakinioti et al. [55] presented the Spong3D research project within which a 3D-printed façade panel able to regulate the indoor temperature of a building throughout the year was developed. The printing process applied was Fused Deposition Modelling (FDM), and the material used was polyethene terephthalate glycol modified (PETG). The insulation consists of air cavities in the core of the panel, and the heat storage is a water-based liquid placed in the façade when and where needed each time of the year to absorb or release heat. The final large-scale prototype has a thermal conductivity coefficient $(\lambda)$ of $0.1 \mathrm{~W} /(\mathrm{mK})$, which means that $33 \mathrm{~cm}$ of insulation is needed to obtain thermal transmittance of the element (U-value) of $0.30 \mathrm{~W} /\left(\mathrm{m}^{2} \mathrm{~K}\right)$.

Kaszynka et al. [11] determined the thermal properties of a 3D-printed wall with $5 \mathrm{~cm}$ of mineral wool as an outer insulation layer and $14 \mathrm{~cm}$ of polyurethane foam as the insulation between the 3D-printed concrete layers of $3 \mathrm{~cm}$ each. The mineral wool, the polyurethane foam and the concrete mixture, respectively, revealed $\lambda$ of $0.0321,0.0384$ and $1.1522 \mathrm{~W} / \mathrm{mK}$, which implies an overall wall U-value of $0.18 \mathrm{~W} / \mathrm{m}^{2} \mathrm{~K}$. Furthermore, a simulation performed showed that the linear thermal bridge at the corner of two outer walls does not occur; however, for relative humidity above $60 \%$, the linear thermal bridge would result in the condensation on the surface, resulting in the development of fungus and mould.

In a distinct study, Gosselin et al. [56] developed a concrete mix for 3D printing containing original Portland cement CEM I $52.5 \mathrm{~N}(30-40 \% \mathrm{w})$, crystalline silica $(40-50 \% \mathrm{w})$, silica fume $(10 \% \mathrm{w})$ and limestone filler $(10 \% \mathrm{w})$ and stated that the shape of the structure has an influence on its heat transfer, while Lim et al. [16] mentioned that voids intern to the printed structure could be used for thermal insulation, weight minimisation or as a conduit for building services.

As stated by Yang et al. [57], most commercially available insulation materials, such as expanded polystyrene (EPS) or extruded polystyrene (XPS) that are commonly plateshaped, and flexible wool-shaped materials such as glass wool and rock wool generally used as pressed plates, are difficult to apply to nonlinear structures, which limits the selection of the insulation and, therefore, can lead to the lower energy performance of the building as higher energy is required for the thermal comfort of the inhabitants.

Nevertheless, printed walls not only have to meet mechanical and rheological parameters but also must satisfy the requirements of the building code, which include thermal aspects as overheating in summer and heat loss in winter.

He et al. [58] developed a modular 3D-printed vertical concrete green wall system (3D-VtGW). The numerical results showed that the building with $3 \mathrm{D}-\mathrm{VtGW}$ reduces wall exterior surface temperature and through-wall heat flux, i.e., this wall presents a potential for saving energy and increase thermal comfort.

Overall, a lack of knowledge related to the thermal behaviour of additively manufactured building elements was verified, mainly due to the fact that research projects are at an early stage of application, focused on structural design and durability concerns. However, with the fast evolution of additive manufacturing methodologies for building construction, thermal insulation represents a knowledge gap that must be closed.

Currently, thermal concerns and demands are at the structural design level; therefore they cannot be overlooked. Thus, considering the need to move towards occupant comfort, 
it is important to highlight the need to study the development of thermal insulation materials suitable for 3D printing or, in a distinct approach, the optimisation of the structure shape and printing path design to increase the thermal performance of the building, without disregarding that the material must be self-supporting during printing with the purpose of avoiding collapse.

\section{Conclusions}

The 3D printing of concrete has endured a significant evolution during recent years, and the number of projects completed and in-progress shows that this technology will most likely become part of the construction industry in the next 5-10 years. The advantages for the sector are clear-higher efficiency, fewer resources needed, reduction of waste, fewer accidents and more design freedom.

Nonetheless, many challenges need to be addressed, and solutions are yet to be found for the process to reach full up-scale. These include a proper assessment of the total costs and environmental impact, decrease the dependency on cement as a binder and full control of the fresh behaviour.

Finally, an area that certainly requires much more attention is the thermal behaviour of 3D-printed buildings. With Europe moving towards zero-energy buildings, new 3DP structures must fit within these requirements, something that can only be achieved with extensive research on thermal behaviour and design optimisation $[59,60]$.

Author Contributions: All the authors contributed to the development, analysis, writing and revision of the paper: conceptualisation, A.S.G., S.S.L. and J.M.P.Q.D.; methodology, A.S.G., S.S.L. and J.M.P.Q.D.; formal analysis, A.S.G. and J.M.P.Q.D.; investigation, A.S.G. and S.S.L.; writing-original draft preparation, A.S.G. and J.M.P.Q.D.; writing-review and editing, S.S.L. and J.M.P.Q.D.; visualisation, A.S.G. and S.S.L.; supervision, A.S.G., S.S.L. and J.M.P.Q.D. All authors have read and agreed to the published version of the manuscript.

Funding: This work is financed by National Funds through the FCT—Fundação para a Ciência e a Tecnologia (Portuguese Foundation for Science and Technology) within the project MIT-EXPL/TDI/0041/2019. In addition, this work was financially supported by: Base Funding - UIDB/04708/2020 of the CONSTRUCTInstituto de I\&D em Estruturas e Construções—funded by national funds through the FCT/MCTES (PIDDAC).

Institutional Review Board Statement: Not applicable.

Informed Consent Statement: Not applicable.

Data Availability Statement: The data that support the findings of this study are available upon request from the authors.

Acknowledgments: Department of the Built Environment, Unit of Structural Design, Eindhoven University of Technology, Eindhoven.

Conflicts of Interest: The authors declare no conflict of interest.

\section{References}

1. Feng, P.; Meng, X.; Chen, J.F.; Ye, L. Mechanical properties of structures 3D printed with cementitious powders. Const. Build Mater. 2015, 93, 486-497. [CrossRef]

2. Tay, Y.W.D.; Panda, B.; Paul, S.C.; Noor Mohamed, N.A.; Tan, M.J.; Leong, K.F. 3D Printing Trends in Building and Construction Industry: A Review. Virtual Phys. Protot. 2017, 12, 261-276. [CrossRef]

3. Dixit, M.K. Life cycle recurrent embodied energy calculation of buildings: A review. J. Clean. Prod. 2018, 209, 731-754. [CrossRef]

4. Kim, J.B.; Jeong, W.; Clayton, M.J.; Haberl, J.S.; Yan, W. Developing a physical BIM library for building thermal energy simulation. Autom. Constr. 2015, 50, 16-28. [CrossRef]

5. Gourlis, G.; Kovacic, I. Building Information Modelling for analysis of energy efficient industrial buildings-A case study. Renew. Sustain. Energy Rev. 2017, 68, 953-963. [CrossRef]

6. Warszawski, A.; Navon, R. Implementation of Robotics in Building: Current Status and Future Prospects. J. Constr. Eng. Manag. ASCE 1998, 124, 31-41. [CrossRef]

7. Alwi, A.; Karayiannis, S.; Starkey, B.; Gardner, M.; Reodique, K.; Varley, T. Construction, MegaScale 3D Printing; University of Surrey: Guildford, UK, 2013; pp. 199-200. 
8. Wu, P.; Wang, J.; Wang, X. A critical review of the use of 3-D printing in the construction industry. Autom. Constr. 2016, 68, 21-31. [CrossRef]

9. Buswell, R.A.; Soar, R.C.; Gibb, A.G.F.A. Thorpe, Freeform construction: Mega-scale rapid manufacturing for construction. Autom. Constr. 2007, 16, 224-231. [CrossRef]

10. De Schutter, G.; Lesage, K.; Mechtcherine, V.; Nerella, V.N.; Habert, G.; Agusti-Juan, I. Vision of 3D printing with concreteTechnical, economic and environmental potentials. Cem. Concr. Res. 2018, 112, 25-36. [CrossRef]

11. Kaszynka, M.; Olczyk, N.; Techman, M.; Skibicki, S.; Zielinski, A.; Filipowicz, K.; Wroblewski, T.; Hoffmann, M. ThermalHumidity Parameters of 3D Printed Wall. IOP Conf. Ser. Mater. Sci. Eng. 2019, 471, 082018. [CrossRef]

12. Bell, B. Digitally Fabricated Concrete: The Future of Manufacturing is Already Here. 2014. Available online: http: //cdnassets.hw.net/32 /6f /9558d68c461bb6dba4c1f73fa848/ascent-winter-2014-technical-digitally-fabricated-concrete-thefuture-of-manufacturing-is-already-here-tcm77--2125386.pdf (accessed on 15 March 2021).

13. Perkins, I.; Skitmore, M. Three-dimensional printing in the construction industry: A review. Int. J. Constr. Manag. 2015, 15, 1-9. [CrossRef]

14. Khoshnevis, B.; Hwang, D.; Yao, K.T.; Yeh, Z. Mega-scale fabrication by contour crafting. Int. J. Indust. Syst. Eng. 2006, 1, 301-320. [CrossRef]

15. Cesaretti, G.; Dini, E.; De Kestelier, X.; Colla, V.; Pambaguian, L. Building components for an outpost on the Lunar soil by means of a novel 3D printing technology. Acta Astronaut. 2014, 93, 430-450. [CrossRef]

16. Lowke, D.; Dini, E.; Perrot, A.; Weger, D.; Gehlen, C.; Dillenburger, B. Particle-bed 3D printing in concrete constructionPossibilities and challenges. Cem. Concr. Res. 2018, 112, 50-65. [CrossRef]

17. Wolfs, R. 3D Printing of Concrete Structures. Ph.D. Thesis, Eindhoven University of Technology, Eindhoven, The Netherlands, 2015.

18. Lim, S.; Buswell, R.A.; Le, T.T.; Austin, S.A.; Gibb, A.G.F.; Thorpe, T. Developments in construction-scale additive manufacturing processes. Autom. Constr. 2012, 21, 262-268. [CrossRef]

19. Hwang, D.; Khoshnevis, B. An innovative construction process-contour crafting (CC). In Proceedings of the 22nd International Symposium on Automation and Robotics in Construction (ISARC 2005), The Fraunhofer-Informationszentrum Raum und Bau IRB, Ferrara, Italy, 11-14 September 2005.

20. Paolini, A.; Kollmannsberger, S.; Rank, E. Additive manufacturing in construction: A review on processes, applications, and digital planning methods. Addit. Manuf. 2019, 30, 100894. [CrossRef]

21. Khoshnevis, B. Innovative rapid prototyping process makes large sized, smooth surfaced complex shapes in a wide variety of materials. Mater. Technol. 1998, 13, 52-63. [CrossRef]

22. Khoshnevis, B. Automated construction by contour crafting-Related robotics and information technologies. Autom. Constr. 2004, 13, 5-19. [CrossRef]

23. Yossef, M.; Chen, A. Applicability and Limitations of 3D Printing for Civil Structures. In Proceedings of the Conference on Autonomous and Robotic Construction of Infrastructure, Ames, IA, USA, 2-3 June 2015.

24. Le, T.T.; Austin, S.A.; Lim, S.; Buswell, R.A.; Law, R.; Gibb, A.G.F.; Thorpe, T. Hardened properties of high-performance printing concrete. Cem. Concr. Res. 2012, 42, 558-566. [CrossRef]

25. Mechtcherine, V.; Nerella, V.N.; Will, F.; Näther, M.; Otto, J.; Krause, M. Large-scale digital concrete construction-CONPrint3D concept for on-site, monolithic 3D-printing. Autom. Constr. 2019, 107, 102933. [CrossRef]

26. Zhang, J.; Wang, J.; Dong, S.; Yu, X.; Han, B. A review of the current progress and application of 3D printed concrete. Compos. Part A Appl. Sci. Manuf. 2019, 125, 105533. [CrossRef]

27. Shanghai Company Donates 3D Printed Quarantine Wards to Hubei Hospital. Available online: https: / / www.chinadaily.com. cn/a/202002/13/WS5e450172a31012821727758a.html (accessed on 19 February 2020).

28. In World's First 3-D Printed Home Community, Houses Will Be Built in a Day for \$4000. Available online: https://www archdaily.com/891065/in-worlds-first-3d-printed-community-houses-cost-4000-dollars-and-are-built-in-24-hours (accessed on 19 February 2020).

29. World's 1st 3D Printed Neighborhood Being Built in Mexico. Available online: https://www.wbur.org/hereandnow/2020/02/ 06/worlds-first-3d-printed-neighborhood-mexico (accessed on 19 February 2020).

30. U.S. Marines Use 3D Printing to Rapidly Construct Concrete Barrack. Available online: https://3dprintingindustry.com/news / u-s-marines-use-3d-printing-to-rapidly-construct-concrete-barrack-139125 (accessed on 19 February 2020).

31. Duffy, K. 3D Printing A Functional Steel Bridge. 2015. Available online: https://www.manufacturing.net/home/news/13100683 /3d-printing-a-functional-steel-bridge (accessed on 15 March 2021).

32. Zhang, X.; Li, M.; Lim, J.H.; Weng, Y.; Tay, Y.W.D.; Pham, H.; Pham, Q.C. Large-scale 3D printing by a team of mobile robots. Autom. Constr. 2018, 95, 98-106. [CrossRef]

33. Brian, K. World's First 3D Printed Office Building, Complete with 3D Printed Furniture \& Interior to Be Built in Dubai-3DPrint.com. 2015. Available online: http:/ /3dprint.com/77550/dubai-3d-printed-office (accessed on 15 March 2021).

34. Brittney, S. A Shanghai-Based WinSun 3D Prints 6-Story Apartment Building and an Incredible Home. 2015. Available online: https://3dprint.com/38144/3d-printed-apartment-building (accessed on 15 March 2021).

35. Eddie, K. Lewis Grand Hotel Erects World's First 3D Printed Hotel, Plans to Print Thousands of Homes in the Philippines Next. 2015. Available online: https://3dprint.com/94558/3d-printed-hotel-lewis-grand (accessed on 15 March 2021). 
36. Li, X.; Zhang, N. Preparation and microstructural characterization of a novel 3D printable building material composed of copper tailings and iron tailings. Constr. Build. Mater. 2020, 249, 118779. [CrossRef]

37. Ma, G. A novel additive mortar leveraging internal curing for enhancing interlayer bonding of cementitious composite for 3D printing. Constr. Build. Mater. 2020, 244, 118305. [CrossRef]

38. Li, Z.; Hojati, M.; Wu, Z.; Piasente, J.; Ashrafi, N.; Duarte, J.P.; Nazarian, S.; Bilén, S.G.; Memari, A.M.; Radlińska, A. Fresh and Hardened Properties of Extrusion-Based 3D-Printed Cementitious Materials: A Review. Sustainability 2020, 12, 5628. [CrossRef]

39. Rahul, A.V.; Santhanam, M. Evaluating the printability of concretes containing lightweight coarse aggregates. Cem. Concr. Compos. 2020, 109, 103570. [CrossRef]

40. Yang, H.; Li, W.; Che, Y. 3D Printing Cementitious Materials Containing Nano-CaCO3: Workability, Strength, and Microstructure. Front. Mater. 2020, 7, 260. [CrossRef]

41. Khalil, A.; Xiangyu, W.; Kemal, C. 3D Printable Magnesium Oxide Concrete: Towards Sustainable Modern Architecture. Addit. Manuf. 2020, 33, 101145. [CrossRef]

42. Falliano, D.; De Domenico, D.; Ricciardi, G.; Gugliandolo, E. 3D-printable lightweight foamed concrete and comparison with classical foamed concrete in terms of fresh state properties and mechanical strength. Constr. Build. Mater. 2020, $254,119271$. [CrossRef]

43. Rehman, A.U.; Lee, S.-M.; Kim, J.-H. Use of municipal solid waste incineration ash in 3D printable concrete. Process Saf. Environ. Prot. 2020, 142, 219-228. [CrossRef]

44. Gomaa, M.; Wassim, J.; Alejandro, V.R.; Veronica, S. 3D printing System for Earth-based Construction: Case Study of Cob. Autom. Constr. 2021, 124, 103577. [CrossRef]

45. Ting, G.H.A.; Tay, Y.W.D.; Qian, Y.; Tan, M.J. Utilization of recycled glass for 3D concrete printing: Rheological and mechanical properties. J. Mater Cycles Waste Manag. 2019, 21, 994-1003. [CrossRef]

46. Buswell, R.A.; Leal de Silva, W.R.; Jones, S.Z.; Dirrenbergerd, J. 3D printing using concrete extrusion: A roadmap for research. Cem. Concr. Res. 2018, 12, 37-49. [CrossRef]

47. Chen, Y.; Veer, F.; Çopuroğlu, O. A critical review of 3D concrete printing as a low $\mathrm{CO}_{2}$ concrete approach. Heron 2017, 62, 167-194.

48. Weller, C.; Kleer, R.; Piller, F.T. Economic implications of 3D printing: Market structure models in light of additive manufacturing revisited. Int. J. Prod. Econ. 2015, 164, 43-56. [CrossRef]

49. Agustí-Juan, I.; Müller, F.; Hack, N.; Wangler, T.; Habert, G. Potential benefits of digital fabrication for complex structures: Environmental assessment of a robotically fabricated concrete wall. J. Clean. Prod. 2017, 154, 330-340. [CrossRef]

50. Suiker, A.S.J. Mechanical performance of wall structures in 3D printing processes: Theory, design tools and experiments. Int. J. Mech. Sci. 2018, 137, 145-170. [CrossRef]

51. Zhang, Y.; Zhang, Y.; Liu, G.; Yang, Y.; Wu, M.; Pang, B. Fresh properties of a novel 3D printing concrete ink. Constr. Build. Mater. 2018, 174, 263-271. [CrossRef]

52. Panda, B.; Unluer, C.; Tan, M.J. Investigation of the rheology and strength of geopolymer mixtures for extrusion-based 3D printing. Cem. Concr. Compos. 2018, 94, 307-314. [CrossRef]

53. Panda, B.; Tan, M.J. Experimental study on mix proportion and fresh properties of fly ash based geopolymer for 3D concrete printing. Ceram. Int. 2018, 44, 10258-10265. [CrossRef]

54. Yoon, J. SMP Prototype Design and Fabrication for Thermo-responsive Façade Elements. J. Facade Des. Eng. 2019, 7, 41-61.

55. Sarakinioti, M.V.; Konstantinou, T.; Turrin, M.; Tenpierik, M.J.; Loonen, R.C.G.M.; de Klijn-Chevalerias, M.L.; Knaack, U. Development and prototyping of an integrated 3D-printed façade for thermal regulation in complex geometries. J. Facade Des. Eng. 2018, 6, 29-40.

56. Gosselin, C.; Duballet, R.; Roux, P.; Gaudilliere, N.; Dirrenberger, J.; Morel, P. Large-scale 3D printing of ultra-high performance concrete-A new processing route for architects and builders. Mater. Des. 2016, 100, 102-109. [CrossRef]

57. Yang, S.; Wi, S.; Park, J.H.; Cho, H.M.; Kim, S. Novel proposal to overcome insulation limitations due to nonlinear structures using 3D printing: Hybrid heat-storage system. Energ. Build. 2019, 197, 177-187. [CrossRef]

58. He, Y.; Zhang, Y.; Zhang, C.; Zhou, H. Energy-saving potential of 3D printed concrete building with integrated living wall. Energy Build. 2020, 222, 110110. [CrossRef]

59. Pessoa, S.; Guimarães, A.S.; Lucas, S.S.; Simões, N. 3D printing in the construction industry-A systematic review of the thermal performance in buildings. Renew. Sustain. Energy Rev. 2021, 141, 110794. [CrossRef]

60. Pessoa, S.; Guimarães, A.S. The 3D printing challenge in buildings. In Proceedings of the 12th Nordic Symposium on Building Physics (NSB 2020), E3S Web of Conferences, Tallinn, Estonia, 6-9 September 2020; p. 172. 